\title{
Evaluation of the intrinsic innervation of the internal anal sphincter using electrical stimulation
}

\author{
M A KAMM, J E LENNARD-JONES, AND R J NICHOLLS
}

From St Mark's Hospital, London

SUmmary Stimulation of the rectal mucosa with a bipolar electrode leads to relaxation of the internal anal sphincter. Intraoperative studies in two subjects showed that transmission of the impulse was independent of extrinsic nerves and was interrupted by circular myotomy. Characteristics of the reflex were studied in 11 healthy women and 19 women with severe idiopathic constipation. One control subject and two patients did not tolerate the test. In the remainder the stimulus caused a clearly defined fall in internal sphincter pressure. The mean resting maximum anal canal pressure before stimulation was the same in both groups $\left(90\right.$ (10) $v 104$ (7) $\mathrm{cm} \mathrm{H}_{2} \mathrm{O}$, $p=0 \cdot 3$, controls $v$ patients). The threshold stimulus for relaxation $(12(2) v 14(1)$ mamps, $p=0 \cdot 5)$, the maximum percent fall in resting pressure $(43(7) v 46(4) \%, p=0 \cdot 7)$ and the lowest absolute resting pressure produced by stimulation $\left(48(13) v 49(6) \mathrm{cm} \mathrm{H}_{2} \mathrm{O}, \mathrm{p}=0.9\right)$ were the same in both groups. The stimulus required to achieve maximum relaxation was significantly higher in the patient group ( 23 (3) $v 32$ (2) mamps, $p=0.012)$ suggesting abnormal intrinsic innervation of the sphincter in these patients. Electrical stimulation should not replace balloon distension for routine testing of the rectoanal reflex but it may be useful in quantitative studies.

In 1877 Gowers described relaxation of the anal canal in response to intrarectal balloon distension,' and this reflex was later confirmed by Denny-Brown.' Although the rectoanal reflex has traditionally been demonstrated using their methods, a recent report has shown that it can also be elicited by electrical stimulation of the rectal mucosa. We wished to confirm this report and define the characteristics of the electrically induced anal relaxation.

\section{Methods}

SUBJECTS

Eleven healthy women (mean age 31 years, range 2347) without gastrointestinal complaints were studied as controls. Nineteen women with severe idiopathic constipation (mean age 32 years, range 20-42, duration of constipation $>$ three years) were also studied. All patients had infrequent bowel actions, with a spontaneous stated bowel frequency range of one to four weeks, and all suffered from difficulty

Address for correspondence: Dr M Kamm, St Mark's Hospital, City Road, London ECIV 2PS.

Accepted for publication 8 December 1988. with rectal evacuation and abdominal pain. All patients had a normal diameter rectum and colon on barium enema.

Two other subjects were studied intraoperatively to determine the pathway of the electrically induced reflex. Both were men, aged 43 and 51, undergoing restorative proctocolectomy for ulcerative colitis.

The study was approved by the City and Hackney Health Authority Ethics Committee in September 1987, and all subjects gave informed consent.

No bowel preparation was administered. A digital examination was performed and the study proceeded only if the lower rectum was empty. The subjects were studied in the left lateral position, apart from the two intraoperative studies which were performed in the lithotomy position.

The resting pressure in the anal canal was measured using a $4 \mathrm{~mm}$ diameter, water filled closed system microballoon connected through $2 \mathrm{~mm}$ noncompliant plastic tubing to a pressure transducer (Gaeltec, UK) and a chart recorder (Graphtec Corporation, Japan). To determine the functional length of the anal sphincter the microballoon was inserted into the rectum and then slowly withdrawn.

A $1 \mathrm{~cm}$ long bipolar ring electrode (Dantec $21 \mathrm{~L} 10$, 
UK) was mounted on a 14 gauge Foley urinary catheter, and inserted into the rectum to lie approximately $6 \mathrm{~cm}$ above the previously measured upper limit of the anal canal. The microballoon was then reintroduced into the rectum and withdrawn slowly, using a stationary pull-through technique at $0.5 \mathrm{~cm}$ intervals, to determine the site of maximum pressure, at which point it was left in position. Two to three minutes was allowed till the anal canal pressure was stable.

The electrode was connected to a constant current stimulator (Neuromatic $2000 \mathrm{M} / \mathrm{C}$, Dantec, UK). This equipment supplies a constant current to the mucosa regardless of the tissue impedance and indicates if adequate contact with the mucosa is broken. The stimulus used had a frequency of $20 \mathrm{~Hz}$ and duration of $1 \mathrm{msec}$; these parameters have been previously established as the minimum required to consistently induce sphincter relaxation electrically. ${ }^{3}$ Stimuli were applied from $2.5 \mathrm{~mA}$ to a maximum of $40 \mathrm{~mA}$, or less if the stimulus was uncomfortable or three successive stimuli produced no further relaxation of the sphincter. The stimuli were applied in increasing increments of $2.5 \mathrm{~mA}$. Each stimulus was applied until maximum relaxation for that amplitude stimulus was achieved and the pressure had started to return to baseline. When three successive stimuli failed to produce any further increase in the extent of relaxation, no further stimulations were performed.

In the two intraoperative studies the reflex was studied before bowel mobilisation. It was then studied again after rectal mobilisation and close rectal dissection down to the anorectal junction, that is after presumed rectal extrinsic denervation. A third attempt at eliciting the reflex was made after a circumferential myotomy was performed at the anorectal junction, leaving the mucosa intact, and with the stimulating electrode lying above the level of the myotomy.

\section{Results}

CONTROL STUDIES AND PATIENTS WITH CONSTIPATION (Table)

One control subject and two patients found the stimulus unpleasant and could not complete the study. The remaining 10 controls and 17 patients form the basis of the results that follow.

In all subjects, except the three who found the study uncomfortable, the threshold for sphincter relaxation was below the threshold for conscious perception of the stimulus. In three other subjects, at a variable stimulus above the relaxation threshold, the sensation was uncomfortable and this induced

Table Change in the resting anal canal pressure in response to rectal mucosal electrical stimulation

\begin{tabular}{lccl}
\hline & Controls & Patients & $p$ Value* \\
\hline Max resting pressure & $90(10)$ & $104(7)$ & $0 \cdot 3(\mathrm{NS})$ \\
$\left(\mathrm{cm} \mathrm{H}_{2} \mathrm{O}\right)$ & {$[5(-160]$} & {$[55-160]$} & \\
Threshold for relaxation & $12(2)$ & $14(1)$ & $0 \cdot 5(\mathrm{NS})$ \\
$\quad($ mamps) & {$[7 \cdot 5-22]$} & {$[5-20]$} & \\
Stimulus for maximum & $23(3)$ & $32(2)$ & 0.012 \\
$\quad$ relaxation (mamps) & {$[12 \cdot 5-27 \cdot 5]$} & {$[10-40]$} & \\
Lowest resting pressure & $48(13)$ & $49(6)$ & $0.9(\mathrm{NS})$ \\
produced (cm $\left.\mathrm{H}_{2} \mathrm{O}\right)$ & {$[9-124]$} & {$[25-96]$} & \\
Max \% fall in resting pressure43(7) & $46(4)$ & $0.7(\mathrm{NS})$ \\
& {$[16-79]$} & {$[15-76]$} & \\
\hline & & & \\
\hline
\end{tabular}

Mean (SEM). Range indicated in square brackets below mean. *Statistical comparison performed using Student's $t$ test. NS $=$ not significant $(p>0 \cdot 05)$.

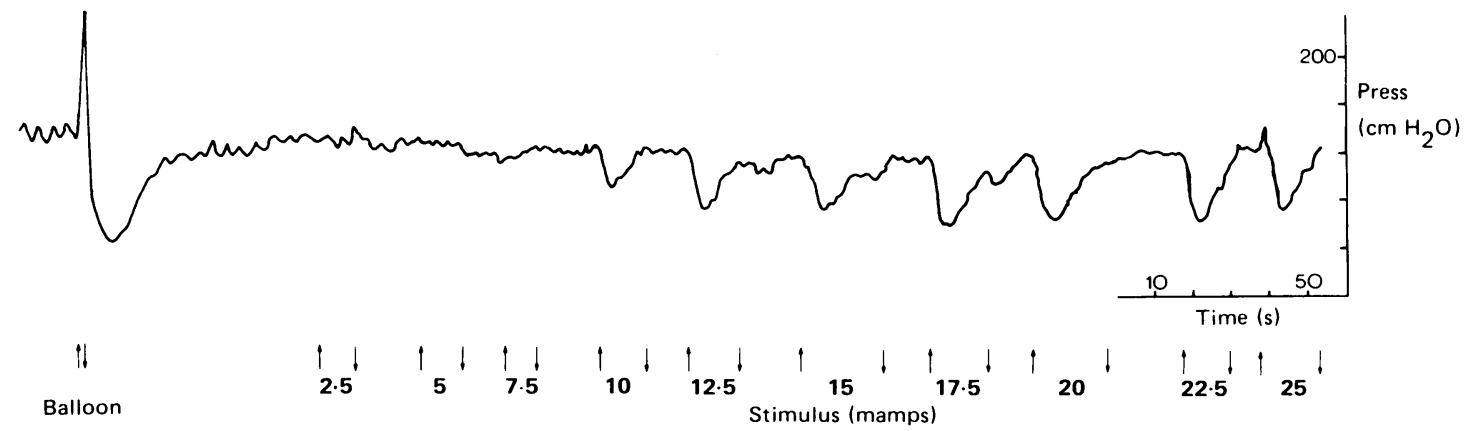

Figure Pressure recording from the anal canal in a patient with severe idiopathic slow transit constipation. Induction of the rectoanal inhibitory reflex by acute intrarectal balloon distension with $50 \mathrm{ml}$ of air has been shown, followed by electrically induced relaxation. The stimulus threshold for sphincter relaxation is at 10 mamp. There was no further increase in sphincter relaxation with stimuli greater than 22.5 mamp. The stimulus was first consciously perceived at 25 mamp, and at that stimulus a brief rise in anal canal pressure can be seen due to external sphincter and puborectalis muscle contraction, followed by internal sphincter relaxation. 
momentary voluntary sphincter contraction (external sphincter), followed by typical sphincter relaxation. This occurred at levels of stimulation which had already produced maximum relaxation, however, as judged by three successive stimuli in which the extent of relaxation did not change, and did therefore not limit the study or influence the results.

The baseline resting pressure profile of the internal sphincter was characterised by a relatively flat trace, although a few subjects showed some slow wave undulation. Stimulation produced a sharp fall in sphincter pressure that was easily recognisable (Figure). With continued stimulation at any amperage level above the relaxation threshold, the sphincter response was characterised by relaxation which persisted until the sphincter became refractory and the pressure returned to a baseline just below the previous baseline. The stimulus was then turned off.

With repeated stimulation there was a slight drift in baseline pressure, usually amounting to $10-15 \%$ of the original resting pressure. The amount of pressure reduction produced by each stimulus was therefore measured from the baseline preceding that stimulus.

The mean maximum anal canal resting pressure prior to the beginning of stimulation was not significantly different for controls compared to patients. The mean minimum stimulus required to produce sphincter relaxation was not significantly different for the two groups, and the range was similar (Table).

The mean maximum percentage reduction in pressure produced was not significantly different for the two groups. Similarly, the mean lowest absolute pressure produced by stimulation was not significantly different for the two groups. The stimulus required to produce maximum relaxation, however, was significantly greater in the patient group.

\section{INTRAOPERATIVE STUDIES}

In the two intraoperative studies, the presence of an electrically induced reflex was confirmed before the bowel being mobilised, and was still present after rectal mobilisation and close dissection. The reflex was abolished in both cases, however, by circumferential myotomy.

\section{Discussion}

The traditional method for showing the rectoanal inhibitory reflex relies on rapid balloon distension in the rectum. The stimulus is difficult to standardise because of variation in the rate of balloon distension as well as individual variation in the rectal diameter and rectal wall compliance. The electrical induction of this reflex was first described by Nagasaki et al as a means of excluding Hirschsprung's disease in children with a megarectum. ${ }^{3}$ Our study has con- firmed that relaxation of the internal anal sphincter can be induced by electrical stimulation of the rectal mucosa, and has established the stimulation parameters for the relaxation threshold and maximum relaxation in healthy women. We have also shown, by intraoperative studies, that the pathway mediating this electrically induced relaxation is within the wall of the anorectum.

Penninckx $\mathrm{et} \mathrm{al}^{4}$ studied the electrically induced relaxation of the internal sphincter using in vitro preparations of the anorectum of cats. Electrical stimulation of rectal mucosa produced anal sphincter relaxation which could be blocked by tetrodotoxin, showing that neural elements are essential for the reflex to occur. They also showed that ganglion cells, muscarinic cholinergic receptors and non-adrenergic non-cholinergic neurones are required for the reflex, and that the neural arrangement resembles the normal peristaltic reflex. Schang and Devroede studied the electrical activity in the distal large bowel while simultaneously measuring anal pressures in human subjects. ${ }^{5}$ They observed sigmoid myoelectrical spike activity correlating with propulsive motor activity and subsequent internal sphincter relaxation typical of normal peristalsis.

There is a lack of agreement about the nature and effect of the extrinsic innervation of the internal sphincter. The internal sphincter receives parasympathetic supply from the sacral outflow and sympathetic supply from the thoracolumbar outflow. The resting anal pressure decreases during high, but not low, spinal or epidural anaesthesia, ${ }^{67}$ indicating a tonic excitatory sympathetic input, but no tonic parasympathetic input, to the internal sphincter. Meunier and Mollard, however, found a lower resting anal pressure in patients with loss of sacral outflow, suggesting a tonic parasympathetic input in addition. ${ }^{\times}$Carlstedt et al showed internal sphincter contraction in response to pelvic sympathetic nerve stimulation, ${ }^{7}$ but Lubowski et $a l^{9}$ and Shepherd and Wright " reported sphincter relaxation. These differences may relate to different stimulation parameters, and hence the possible recruitment of different nerve fibres, sphincter fatigue, or even the release of different neurotransmitters. There are no currently available tests which assess the integrity of the extrinsic innervation of the sphincter.

We applied a mucosal electrical stimulus to the rectum of patients with severe idiopathic constipation in order to assess the responsiveness of their intramural plexuses. The increased stimulus required to achieve the same degree of sphincter relaxation in the patient group as in the controls suggests a functional abnormality of the intramural pathway. This complements the findings by Baldi et al in which the percent reduction of anal pressure for a fixed 
volume balloon distension was reduced in constipated subjects," and the findings of Read et al in which the balloon volume threshold for sustained sphincter inhibition was raised in constipated subjects." Whether the functional disturbance involves the intramural plexuses or the inhibitory innervation of the sphincter is unknown. The myenteric plexus in patients with severe constipation appears morphologically abnormal with silver staining,,$^{1.3}$ but to our knowledge no studies have examined its responsiveness in vivo.

Electrical stimulation is an alternative to balloon distension for eliciting the recto-anal reflex. It is less suitable as a routine test because the apparatus needed is more complex and the stimulus can be uncomfortable. Electrical stimulation may be more appropriate than distension in quantitative studies, however, as its effect does not depend on rectal size, rectal wall compliance or the physical characteristics of the balloon. We believe this is the first in vivo use in man of electrical stimulation to quantitatively evaluate neural pathways within the gut wall.

M A Kamm was supported by the St Mark`s Research Foundation. This work was presented at a meeting of the British Society of Gastroenterology in March 1988. The authors wish to thank Dr M Swash for helpful comments on the manuscript.

\section{References}

1 Gowers WR. The automatic action of the sphincter ani. Proc R Soc Lond 1877; 26: 77-84.

2 Denny-Brown D. Robertson EG. An investigation of the nervous control of defaccation. Brain 1935; 58: 256310 .

3 Nagasaki A. Ikeda K. Suita S. Sumitomo K. Induction of the rectoanal reflex by electrical stimulation. A diagnostic aid for Hirschsprung's disease. Dis Colon Rectum 1984: 27: 598-60)1.

4 Penninckx FM. Mebis JH, Kerremans RP. The rectoanal reflex in cats analysed in vitro. Scand $J$ Gastroenterol 1982: 17 [suppl 71]: 147-9.

5 Schang JC. Devroede G. Myoelectric propagating spike bursts in the sigmoid colon elicit the rectoanal inhibitory reflex [Abstract]. Gastroenterology 1988; 94: A4()3.

6 Frenckner B, Ihre T. Influence of autonomic nerves on the internal anal sphincter in man. Gut 1976; 17: 306-12.

7 Carlstedt A. Nordgren S. Fasth S. Appelgren L. Hulten L. Sympathetic nervous influence on the internal anal sphincter and rectum in man. Int J Colorectal Dis 1988; 3: 90-5.

8 Meunier P. Mollard P. Control of the internal anal sphincter (manometric study with human subjects). Pflugers Arch 1977: 370: 233-9.

9 Lubowski DZ. Nicholls RJ. Swash M. Jordan MJ. Neural control of internal anal sphincter function. Br J Surg 1987: 74: 668-70.

10 Shepherd JJ. Wright PG. The response of the internal anal sphincter in man to stimulation of the presacral nerve. Am J Dig Dis 1968: 13: 421-7.

11 Baldi F. Ferrarini F. Corinaldesi R, et al. Function of the internal anal sphincter and rectal sensitivity in idiopathic constipation. Digestion 1982; 24: 14-22.

12 Read NW. Timms JM. Barfield LJ, Donnelly TC, Bannister JJ. Impairment of defecation in young women with severe constipation. Gastroenterology 1986: 90: 536() .

13 Krishnamurthy S. Schuffler MD, Rohrmann CA. Pope CE II. Severe idiopathic constipation is associated with a distinctive abnormality of the colonic myenteric plexus. Gastroenterology 1985: 88: 26-34. 